\title{
Contributions of a Mandatory Internship Course to an Engineering Curricu- lum
}

\section{Dr. Arif Sirinterlikci, Robert Morris University}

Dr. Arif Sirinterlikci is a professor of engineering at Robert Morris University. Besides advising Co-Op, Industrial, and Manufacturing Engineering students, he also serves as the Interim Head of the Engineering Department and Director of Engineering Laboratories. Sirinterlikci has been active in ASEE with K12/Pre-college, Manufacturing, Mechanical Engineering, and Engineering Technology Divisions.

\section{Dr. Tony Lee Kerzmann, Robert Morris University}

Dr. Tony Kerzmann received both a bachelor's of arts in physics from Duquesne University and a bachelor's of science in mechanical engineering from the University of Pittsburgh in 2004. After graduating, Kerzmann enrolled in graduate school at the University of Pittsburgh, where he graduated with a master's of science and a doctorate of philosophy in mechanical engineering in 2007 and 2010, respectively. Kerzmann is currently an Assistant Professor and Mechanical Engineering Coordinator at Robert Morris University, where he teaches mechanical engineering courses, as well as courses on alternative energy. His research interests include hybrid concentrating photovoltaic systems, energy system life cycle assessment, renewable energy product development, and active learning. 


\section{Contributions of a Mandatory Internship Course to an Engineering Curriculum}

\section{Introduction}

This engineering department hosts engineering programs in; biomedical, industrial, manufacturing, mechanical, and software engineering. Studies have pointed to the notion that engineers are active learners and therefore hands-on experiences are an important part of their education. ${ }^{1}$ In order to promote hands on and experiential learning, the engineering curriculum has included a mandatory internship course (ENGR 4900 Engineering Practice) in which students receive a letter grade from their instructor with an input from the work supervisor. Over the years many students successfully completed multiple internship experiences logging hundreds of work hours, even though only one 150 hour 3 credits worth of experience can be counted towards their degree.

These internship positions have led this engineering department to place its alumni in wellpaying engineering and manufacturing positions within major industries while yielding high overall job placement rates. In the early years of the ENGR 4900 course almost $100 \%$ of the students worked for local industries to satisfy the requirements of the course. However, increasing enrollment and diversified student goals are shifting some of the placements from industrial based internships to in-house engineering and research projects or off-campus research programs at other institutions. Real world experience, if it is working for industry or if it is completing in-house projects, inherently leads the students to participate in cognitive synthesis as well as evaluation; the two highest levels of Bloom Taxonomy. ${ }^{2}$ These external programs are funded by the National Science Foundation (NSF) Research Experiences for Undergraduates (REU) or the NASA Summer Programs. These research experiences are also treated similarly to the industrial internship positions, since they are under the umbrella of the same course.

This paper will present the undergraduate student criteria for qualification and enrollment procedure, format of the course, three forms of the engineering practice; industrial internships, in-house engineering and research projects, and off-campus research work. A variety of positions and projects will be covered in the paper that are focused on the furthering of the active learning experience for the engineering students through in-house projects, where it is important to allow students to formulate their own ideas about the subject matter using hands-on experiences and engineering knowledge. ${ }^{3}$ The impact on student preparation through faculty course assessment reports (FCARs), student feedback, and work supervisor feedback will also be included in this paper. The additional benefits to the program, including student conference papers, authorships and conference presentations will be discussed in this paper as well.

\section{Undergraduate Student Criteria and Enrollment Procedure}

Following criteria is used by the engineering department for qualifying students for internship through ENGR 4900 Engineering Practice course ${ }^{4}$ :

- Minimum QPA: 2.0 (Good standing)

- Minimum number of credits: 64 (Sophomore standing)

- Must have completed / transferred the following courses: 
○ Calculus sequence: MATH2070 Calculus I, MATH2170 Calculus II \& MATH3090 III

- Basic Engineering (at least three of the following): ENGR1010 Introduction to Engineering, ENGR1610 Statics and Strength of Materials, ENGR2080 Engineering Statistics, ENGR2140 Circuits and Electromagnetics, ENGR2160 Engineering Graphics, ENGR2180 Engineering Materials

o Programming: INFS2184 C++ Programming or equivalent

After qualifying through the criteria above and securing a position, students are required to complete three official forms in addition to submitting their job description and resume to the PPG Industries Career and Leadership Development Center.

- Student Application to Academic Internship Program (AIP): This is completed by the student with demographic and academic background information, the number of credits (1-3) requested for the internship as well as course name and number (ENGR 4900 4902 Engineering Practice) and its academic term. It is approved by the Academic Department Head.

- Employer Guidelines and Information Form: Employer guidelines summarize the AIP program for the employers. Employers need to fill in their contact information as well as information regarding the position including majors required, when and how many majors are needed, and the pay rate if applicable.

- Internship Mutual Letter of Agreement: It is a contract is signed by the employer, student, and internship faculty coordinator or advisor drawing the total hours of work within a 15 week semester as well as the term for the internship. At least 50 hours required for the single credit course ENGR 4901, 100 hours for the two credit course ENGR 4902, and 150 hours for the three credit course ENGR 4900. Students are allowed to stack ENGR 4901 and 4902 to receive ENGR 4900 credit, the only course applicable to the student's check-sheet.

After completing all paperwork, students will still need an electronic course waiver from the department head before they can register.

\section{Course Procedures and Format}

ENGR 4900-4902 set of courses consist of a well-defined and academically supervised engineering experience at an industrial site or in a laboratory setting for working towards completion of a project. They are to immerse students in business and industrial settings that will allow them to apply theoretical concepts learned in the classroom and to solve real world engineering problems 5 .

Engineering Practice courses are considered as communications intensive for the school and add to the preparation of the students along with the four Communications Skills (COSK) courses the students need to take. Course grading is based on the following metric for percentage grade contribution to the overall grade:

- Weekly Log/Journal - 25\% 
- Final Report - 25\%

- Final Seminar Presentation - 10\%

- Employer Evaluation - 35\%

- Other Pertinent Requirements- 5\% (including Student/Internship Coordinator Conference and completion of Student Evaluation Form)

Following grading scale is observed for each course: (94 - 100\%, A), (90- 93\%, A-), (87- 89\%, $\mathrm{B}+),(83-86 \%, \mathrm{~B}),(80-82 \%, \mathrm{~B}-),(77-79 \%, \mathrm{C}+),(70-76 \%, \mathrm{C}),(60-69, \mathrm{D}),(0-59, \mathrm{~F})$

During the course of the internship, the student must develop and maintain a weekly journal, to serve as a tool for recording learning experiences ${ }^{5}$. The journal should also include log of the student's activities and a collection of thoughts and insights gained from the activities. The journal may contain any on-the-job issues or problems and related solutions or courses of action taken. A final report is also mandatory. This is above and beyond the weekly journal. The format and topic(s) of the final report is determined by the student with the approval of the internship coordinator or advisor. The intent of the final report is to document the connection between the student's academic course of study and the problems, issues, challenges or opportunities faced by the employer. Examples of acceptable report topics and formats are listed below. The student is not limited to these examples and is encouraged to be creative in proposing a final report, which meets the intent described above.

- A portfolio of memoranda, reports, statistical analyses, graphics, letters, products and/or other examples of the student's work while serving as an intern.

- Multiple short reports (3-5 pages) or a single detailed report (10-15 pages) documenting research, analyses, or designs undertaken by the student to address engineering problems experienced by the employer. The engineering problem (or problems) studied should be relevant to the student's specialty (Biomedical, Industrial, Manufacturing, Mechanical, \& Software).

- A project proposal bid directed toward an engineering need of the employer. The student is expected to define the problem, propose a scope of work aimed at solving the problem, estimate the resources (labor, equipment, other direct costs, etc.) necessary to carry out the work, and to propose a practical schedule for its completion.

- A case study suitable for use in the relevant Biomedical, Industrial, Manufacturing, Mechanical, \& Software courses taught at the department as well as general engineering subjects. The case would depict an issue or problem facing the employer. The student would review the final case with the employer to assure that the description of the issue or problem did not compromise the confidentiality or competitiveness of the employer.

A seminar will be scheduled at the end of the internship term ${ }^{5}$. At this seminar, students provide a brief presentation (10 - 15 Power Point slides) about their internship experience and answer related questions from the attending faculty and other students within their cohort. The presentations generally confirm that the students are in fact involved in educationally-appropriate engineering tasks. During the seminar, the internship coordinator can clarify, if needed, the course deliverables and administrative evaluative procedures that lead to the internship grades. The seminar also provides the students with an opportunity both to reflect on the value of the 
course work that had prepared them for the internship and to propose any modifications to the courses to improve their preparation.

Employer evaluation is a major part of the students' experience and resulting grade ${ }^{5}$. For that, a site visit is normally scheduled towards the end of the experience. Each visit generally lasts about an hour, during which the internship coordinator meets with both the student and the internship employer. The coordinator typically tours the facility, guided by the student, and inspects the student's work station. Subsequently, the coordinator privately discusses the internship with the student, with both the student and the internship supervisor, and with the supervisor alone. Through these discussions, the coordinator can both verify that the student is being exposed to realistic engineering tasks and ensure that the experience is appropriate to the student's educational interests. Owing to this visit, the coordinator can reinforce with the employer the educational objectives associated with the internship assignment and recommend any improvements for enhancing its educational value. Due to the increasing number of students and placements in faraway locations, the site visits are being replaced with phone interviews and e-mail contact. However, the employers are still asked fill in the same evaluation form, given in Table 1.

The course syllabus states that the internship coordinator or advisor should be made aware of any problems that arise during the internship ${ }^{5}$. The student must schedule at least one conference session with the faculty member, preferably mid-way through the term of employment. Face-toface conferencing is recommended; however, phone conference may be used should any scheduling conflicts arise. The topics to be discussed during this conference would include employment issues, progress on the weekly journal, and progress on the final report. In addition students are required to complete a survey about their experience. This survey (Table 2.) is included in the appendix part of this paper and gages students' view of their experience reinforcing the outcome of the student/advisor-coordinator conference from earlier .

\section{Forms of Engineering Practice}

With increasing enrollments and diversification of student needs, the engineering practice has become a trifold experience:

- In-house projects and experiences

- External research experiences

- Traditional industrial internships (will not be covered with examples)

With the help of funding from Department of Labor PREP program, this engineering department has been able to hire multiple students every semester for multiple years. These students also registered for the ENGR 4900 Engineering Practice course. Each student logged more than 150 hours, by being involved in projects such as Rapid Fabrication of Injection Molding Tooling using the Stereolithography (SLA) system or Total Knee Replacement Development through CNC machining and various Rapid Prototyping Systems including 3D printing/Fused Deposition Modeling (FDM). Additionally, some of these in-house projects are utilized to support faculty members' research agenda and may be unpaid positions. As the projects are completed, students also gain invaluable experiences. The following section is designated to an in-house research 
project:

- In this case the student was a senior in his last semester of his senior year. A pseudocompany by the name of TurboFlow Inc. was created and a project was developed with a list of specific project objectives, as shown below. The objectives listed below were very optimistic considering the student only had one semester to complete them. As such, the student was expected to get as far as possible with the given time and the remaining objectives could be used for future projects.

\section{Project Objectives:}

1. Literature Search - Conduct a literature search on existing turbine blade designs and how to test turbine designs for comparison. This should consist of a paragraph summary for at least 10 scientific journal articles on the subject.

2. SolidWorks Training - Increase proficiency in SolidWorks design and analysis.

3. Turbine Blade Design - Draw 3 new turbine blade designs (based on literature search) for experimental testing using the flow loop in the learning center.

4. RPM Testing - Design an experimental test that will measure the RPMs of the turbine shaft as the TurboFlow is rotating.

5. Electric Generator - Use the RPM test data to determine the best electric motor for generating the optimal electricity from the TurboFlow.

6. Power Output - Install the watt meter circuitry that will be needed to measure the power output from the electric generator.

7. Experimental Testing - Conduct experimental testing on the different TurboFlow turbine designs under varying flow rates.

8. Optimization - Determine the best combination of turbine blade design and electricity generation.

9. Pressure Reduction - Design a system for varying the rotational resistance in the shaft to alter the pressure reduction across the turbine blade.

\section{Student Expectations:}

The student and professor met for the first time and the student was given the list objectives as well as the project statement shown below. A weekly meeting was scheduled between the student and professor and the student was asked to keep a notebook containing project information as well as documentation of his progress. For the final project submission, the student was required to submit a final report in the form of a conference paper and was expected to present his conclusions at the 2012 Sustainable Enterprises of the Future Conference.

\section{Project Statement:}

TurboFlow Inc. has developed a way to extract energy from flowing water in piping. The TurboFlow design utilizes an in-pipe turbine which turns the kinetic energy in the flow of water into electricity. Traditionally a building uses a pressure regulator that reduces the pressure in the incoming water lines so that the pressurized water does not damage any building water fixtures. The pressure regulator uses a spring loaded system where the energy that is extracted is absorbed by the spring and is essentially wasted. The 
TurboFlow design harnesses the wasted energy and converts it to electricity, while reducing the pressure that enters the building.

This internship is focused on optimizing the TurboFlow design in a number of ways.

First, a literature search will be done to foster a fundamental understanding of the subject. Secondly, the intern must design multiple turbine blades with the intent of increasing the efficiency of the system. Third, Experimental testing must be performed with the goal of increasing the energy output of the TurboFlow. Finally, the intern must devise a system to control the pressure difference across the turbine blade. All of these objectives must be met for the intern to receive full course credits.

\section{Project Progress and Conclusions:}

The student was able to conduct an extensive literature search, train himself on the SolidWorks software, design and draw two turbine blades that can be used in the TurboFlow loop (shown below in Figure 1.) for efficiency testing and finally fabricate the two prototype turbine blades. A detailed list of the project accomplishments are listed below.

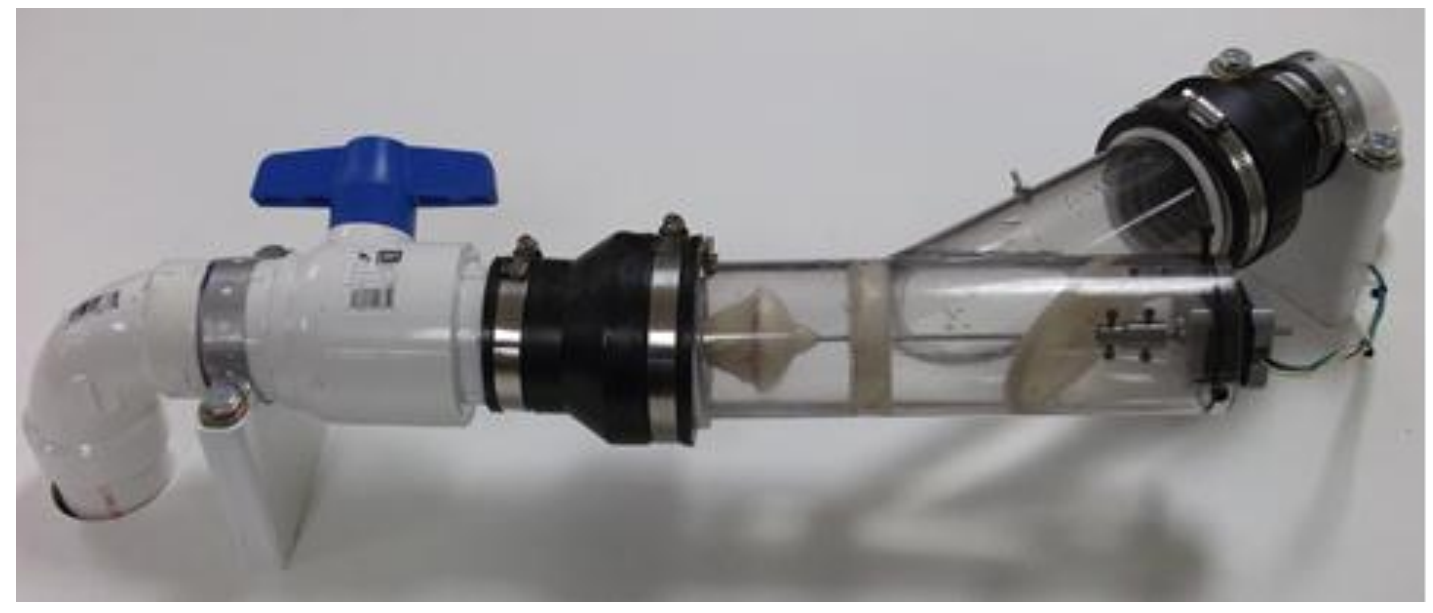

Figure 1. TurboFlow Loop

\section{Project Accomplishments:}

1. Developed understanding of TurboFlow system

2. Conducted extensive literature search

3. Increased SolidWorks drawing proficiency

4. Conducted self-training on SolidWorks flow simulation through tutorials

5. Determined turbine blade designs based on hydraulic diameter

6. Drew 2 turbine blade designs in SolidWorks

7. Used the SolidWorks drawings to fabricate prototype turbine blades using the fused deposition modeling machine in the RMU Rapid Prototyping Lab

8. Submitted a conference paper that was accepted

9. Presented at the 2012 Sustainable Enterprises of the Future Conference

10. Calculated the estimated yearly cost savings for an average hotel in Florida 
The TurboFlow project began as a design that a student engineering design team developed and fabricated for a regional competition. Although the TurboFlow turbine system worked well, the turbine blades were not optimized to maximize power output. In order for the student to contribute to the previous group's work he had to fully understand the system and the research that the previous group conducted. Building upon this knowledge, the student had to conduct an extensive literature search to understand the necessary fluid flow parameters that would be analyzed when comparing multiple turbine blades. This literature covered fluid flow, turbine design and water turbine experimental testing.

After the literature search, the student began honing his skills in 3D CAD drawing using the SolidWorks software. The student had previous experience with SolidWorks, but drawing complex curvature as that found in turbine blades would require higher level drawing skills than those taught in the engineering graphics courses taught at RMU. The student also learned how to conduct a flow simulation using SolidWorks, although a full flow simulation was not conducted on the new turbine designs. Using his new found skills, the student drew 3D models of two turbine blade designs that had the same hydraulic diameter to allow for direct comparison of efficiency, shown below in Figure 2. From the 3D models, the student was able to use the university's Fused Deposition (FDM) Modeling machine to create tow rapid prototyped turbine blades. After a waterproofing process, these parts are then capable of installation directly in the flow loop used for experimental testing.
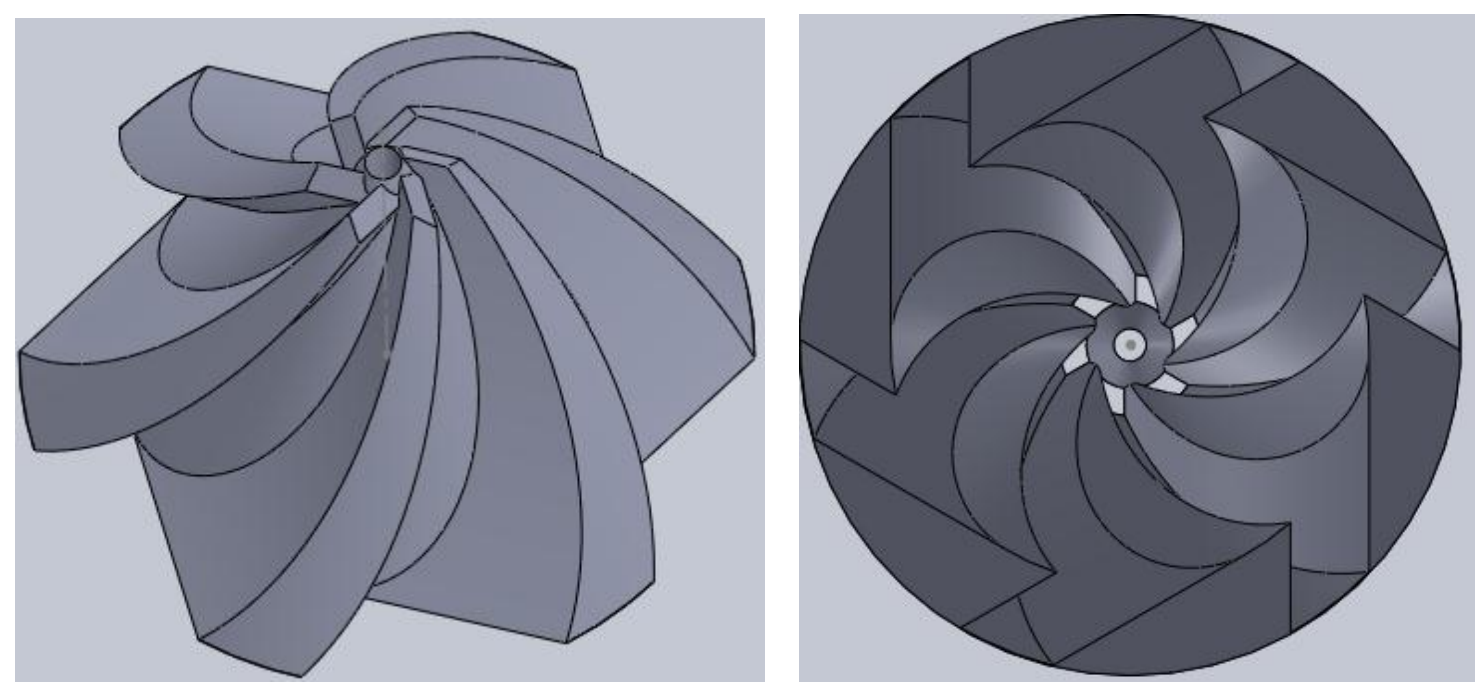

Figure 2. (left) Turbine design where water flows around the outside of the blades. (right) Turbine design where water flows across the blades and through the center.

Finally the student used some educated assumptions and data based on his literature search to determine the estimated cost savings of the TurboFlow if it were installed in an average U.S. hotel. According to the Southwest Florida Water Treatment Plant, hotels and motels in that area use approximately 21,537 gallons of water per day ${ }^{6}$. Using this daily flow rate, and including the estimated TurboFlow efficiency and pressure change 
across the turbine blades the student was able to calculate a theoretical power output for the TurboFlow system. The research group assumed a turbine efficiency of $80 \%$ and a pressure drop of $10 \mathrm{psi}$ across the turbine blades. With a flow rate of 21,537 gal/day; the generator is capable of producing $52 \mathrm{~W}$, or $455.5 \mathrm{kWh} /$ year, and an annual energy savings of approximately $\$ 45$.

Another way of engineering practice becoming popular involves students working outside the university through programs such as NSF REU or NASA Summer Fellowships. The department has students accepted at major research universities including University of Pittsburgh, Carnegie Mellon, Texas A\& M, Northeastern, Vanderbilt, Worchester Polytechnic Institute (WPI), just to name a few in addition to NASA or various Medical Center research opportunities. As a recent example, two students were hired by University of Pittsburgh to either fabricate dental implants or test already fabricated implants. This engineering department helps University of Pittsburgh fabricate mechanically alloyed dental implants and medical fasteners. After being fabricated, these parts are needed to be tested for performance requirements including corrosion and biocompatibility. Engineering students enrolled in ENGR 4900 had worked on testing of the implants at University of Pittsburgh or made new implants using the 3D Printers available at their host institution. Meanwhile another student completed a second NSF REU activity in Tissue Engineering at Vanderbilt University after completing one at WPI. All of these three students presented their findings at the 2012 Biomedical Society (BMES) Annual Meeting held in Atlanta, Georgia.

\section{Course Assessment and Student and Employer Feedback}

Since the interning student numbers are increasing with the booming enrollment, the data relating to their experience becomes more critical. Student survey and employer evaluation results along with final grades have been summarized and analyzed in FCARs, Faculty Course Assessment Reports. The main objective of this effort is to capture the big picture as well as the minor details including student issues of adaptation to the work environment and professionalism, promptness, communication, and evidence of poor preparation at the school. These FCAR documents were used in the previous ABET accreditation cycle and will be used again in the next accreditation cycle. Student performances included in the FCAR reports can be seen in Figure 3 (below) for 58 students who took the ENGR 4900 course between Fall 2010 and Spring 2012. Results indicate excellent performances by the student body. These grades also include internship supervisors' input. This is discussed below in this section.

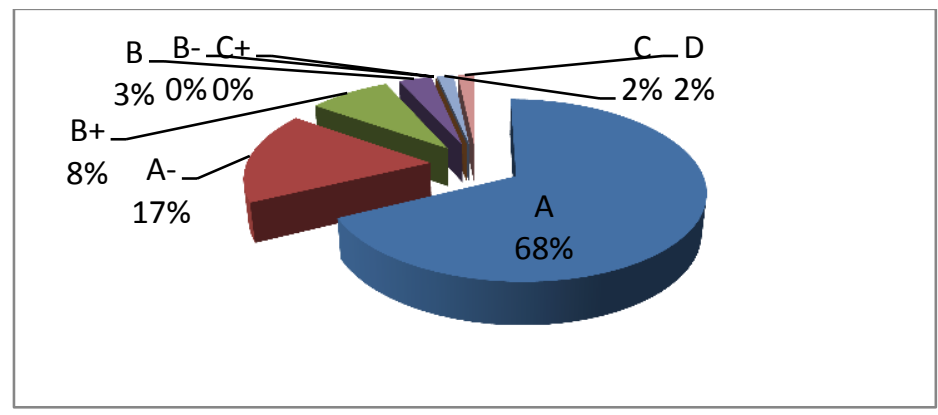

Figure 3. Student grade distribution for 58 students who completed their practice recently 
For the last few years, the lead author has been in charge of the program. Most of the students are satisfied with their experience as the student survey results indicate. A copy of the student survey form is included within the appendix of this paper. A separate form is used collect data for BS in Manufacturing Engineering majors when compared to BS in Engineering students.

Employer satisfaction is also another proof that the program has been successful. Employers have to complete the evaluation form shown in Table 1 (in the appendix) and also are contacted by the internship coordinator or advisor for a phone interview. Three testimonials are given below on three separate students - two mechanical and one industrial who worked for Console Energy, Taggart Global, and Matthews International. These testimonials are the most common, only 1-2\% percentage of students has received negative reviews within the last few years out of about 100 students who have done at least one form of engineering practice.

- "I would give Jason an A to A-. He has more initiative than just about any other intern we have had work here."

- "Thank you for the opportunity to evaluate Zuheir. Zuheir has been invaluable to our project of creating a value stream map over our 3 major processes. Originally I planned to complete 2 of the 3 processes using Zuheir. He took direction well, understood the scope of what we were trying to do, and tirelessly collected and constructed the data into the desired format. In doing so, we moved into VSM creation of the $3^{\text {rd }}$ process. This was neither unexpected nor was it anticipated initially as part of the scope of work. We also used Zuheir to evaluate some process improvement steps within the Finish portion of our overall process. It was my intent to expose Zuheir to as much I.E./Manufacturing Engineering type work as possible. After a brief orientation and training period, Zuheir worked well with very limited supervision.

You asked that I give Zuheir a grade. By all means, he gets an A. He performed the expected work at a level that exceeded my expectations for an intern. We had Zuheir perform work that I would expect an entry level I.E. or Manufacturing Engineer to perform; and he did it in very impressive fashion, considering his academic level. I hope my survey input, and this email, persuade you and the University to give Zuheir the highest possible grade for the work he performed for Matthews. He will make your university very proud once he steps outside the academic world. US Industry needs more people of the quality of Zuheir."

- "In regards to Erik he has been an outstanding employee. He has been very reliable and professional, always coming to work at or before 8 am and staying to or past $5 \mathrm{pm}$ to complete his work. He communicates very well with his immediate co-workers, upper management, other engineers and coworkers and me. He is quick to understand principles taught and always asks questions for clarification or further learning of the concept. He produces quality work, much better than I have seen before in the given internship time period. Taggart has had the distinct opportunity to have Erik as an intern and if given the chance Taggart would like to 
discuss full time employment opportunities with him. For these reasons and many more, I would give Eric an A for his time at Taggart.

Furthermore I'm pleased to see a professor asking for evaluations of his students in an engineering capacity outside of the classroom. Thank you again and if you have any questions about Erik please don't hesitate to contact me."

In addition to the testimonials, the authors would like to present supervisor feedback collected by using Table 1 for 22 students who recently completed their engineering practice. Only at very

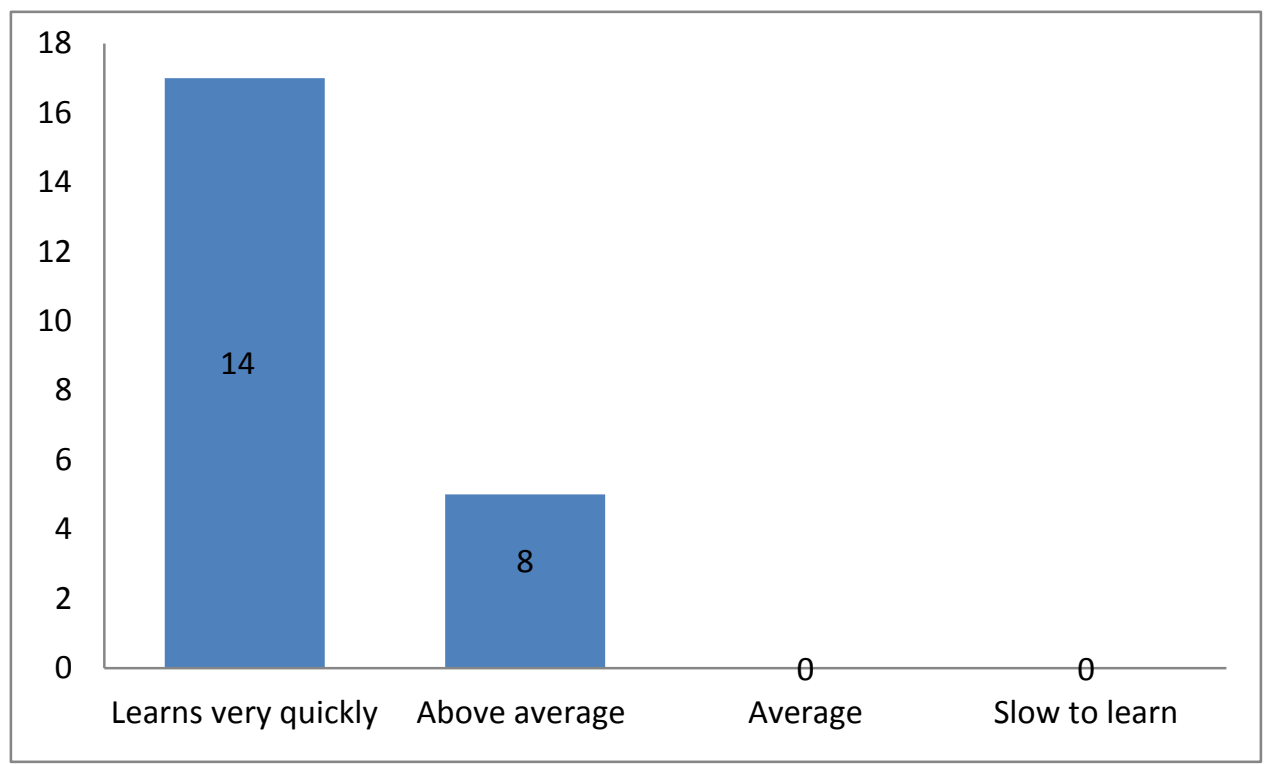

Figure 4. Attitude/Application to Learning

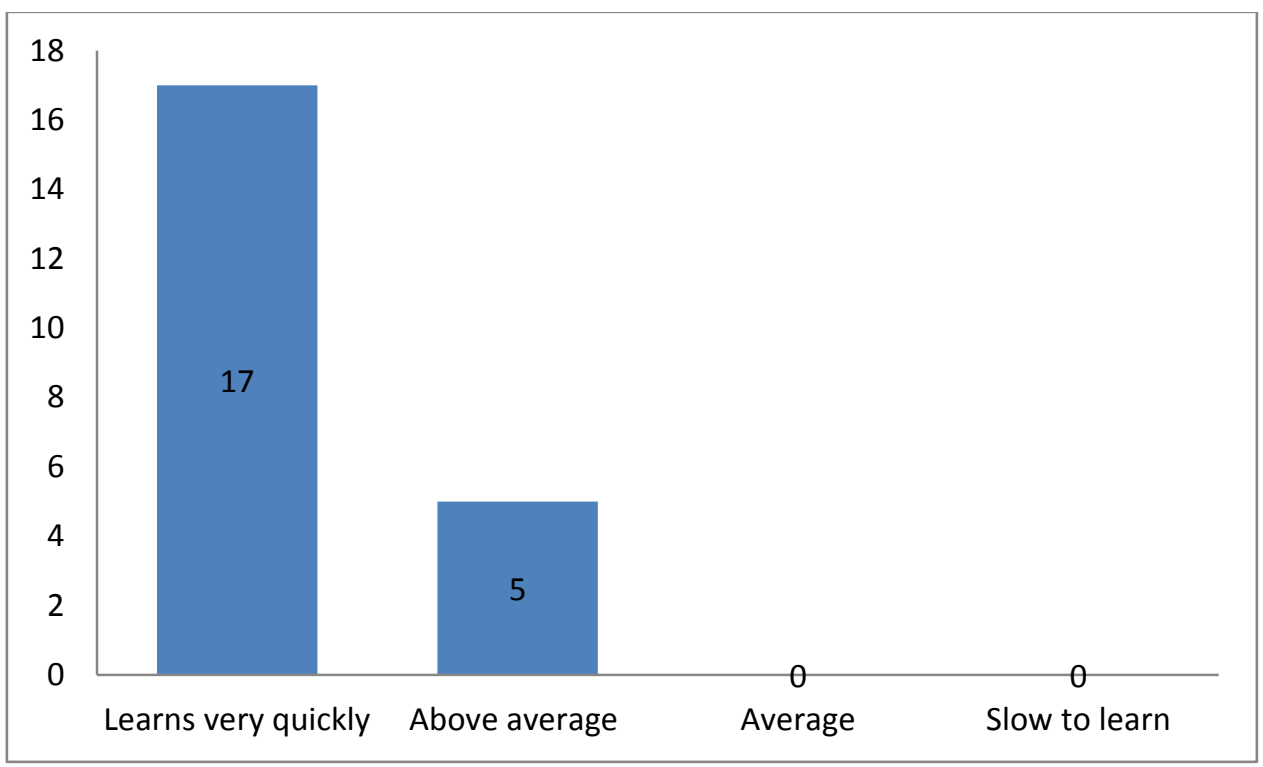

Figure 5. Ability to Learn 


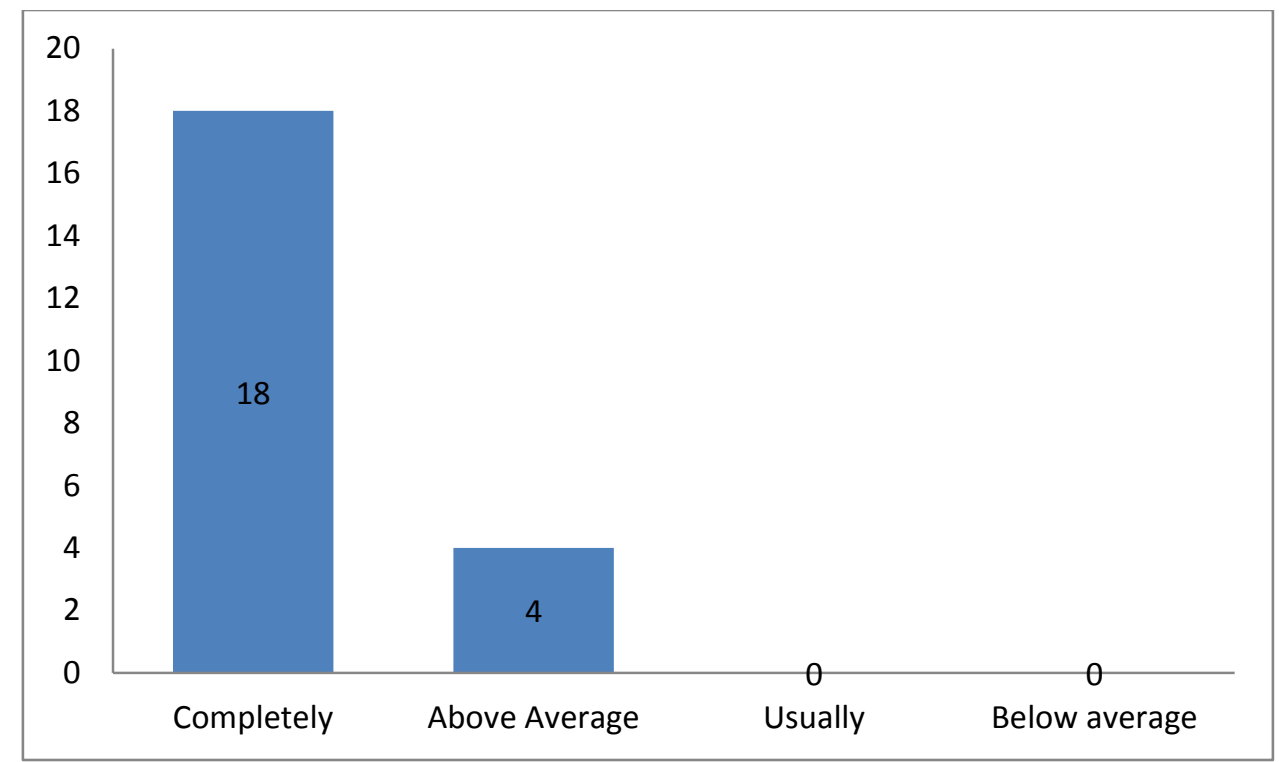

Figure 6. Dependable

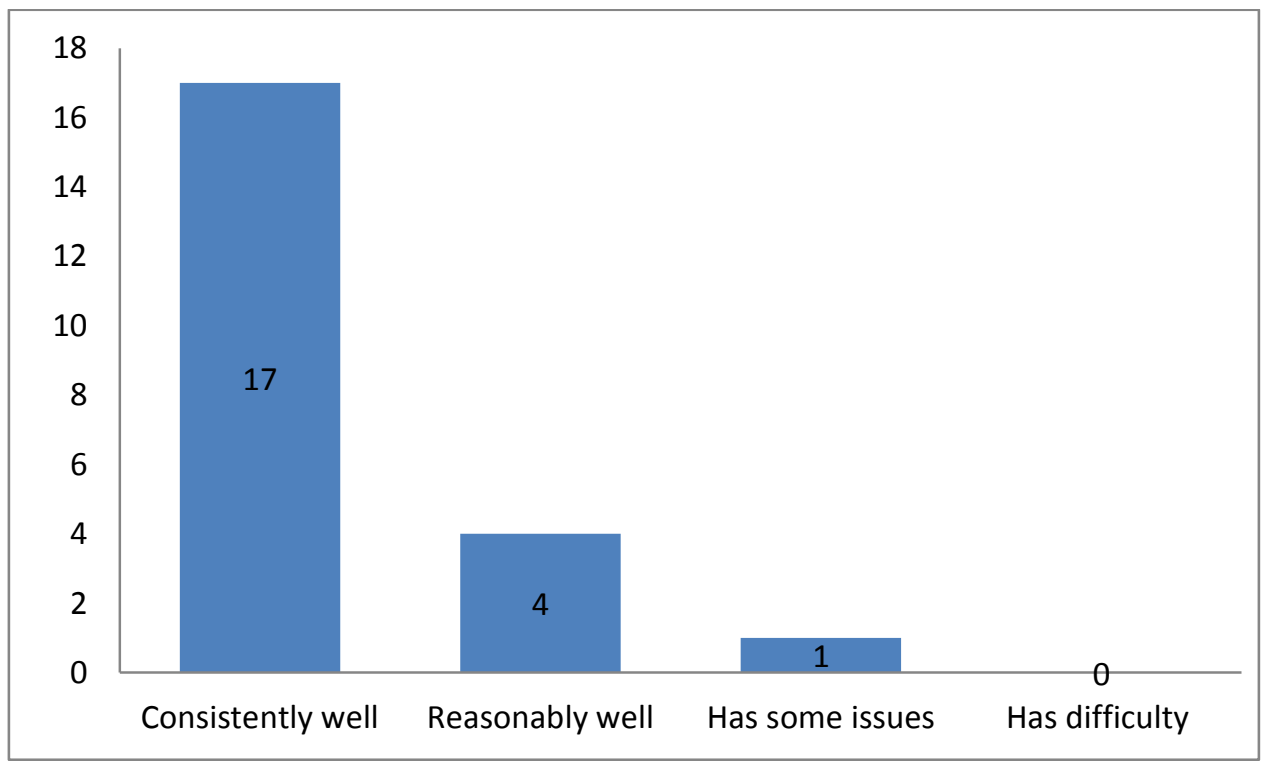

Figure 7. Writing ability






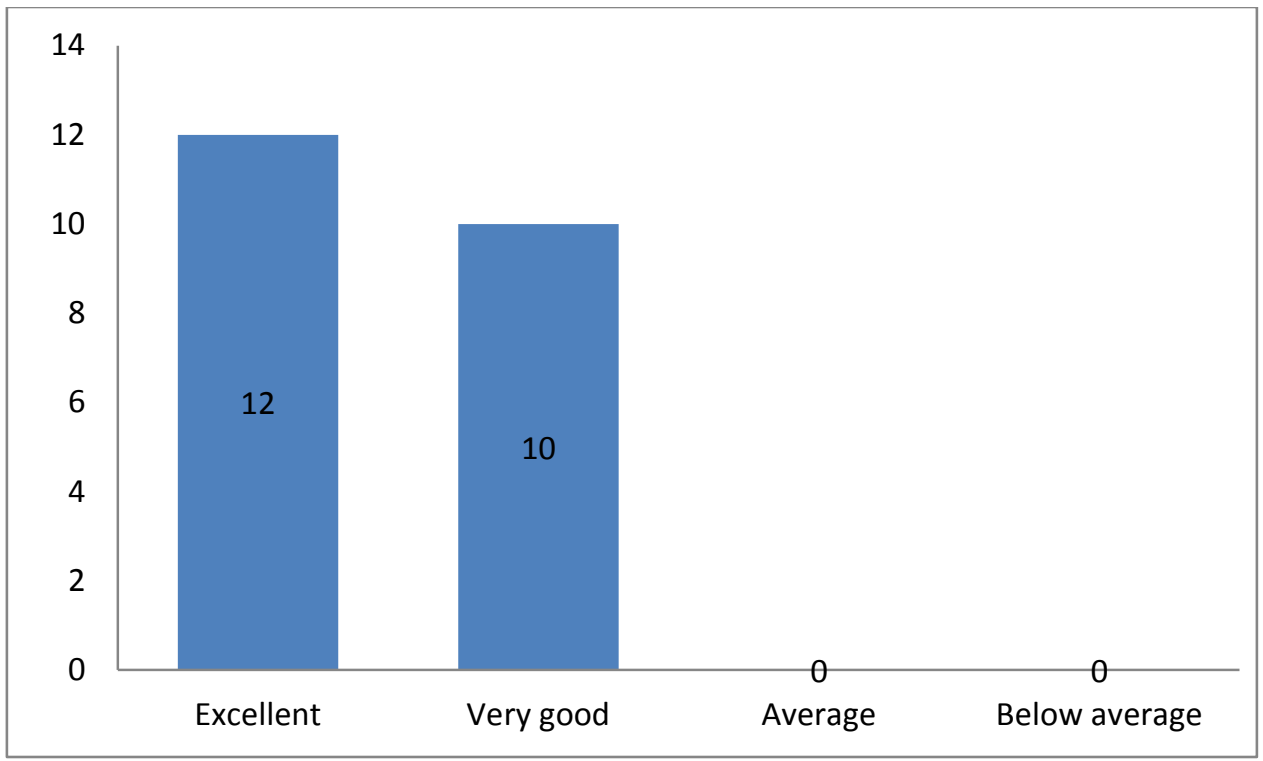

Figure 8. Quality of Work Contributions

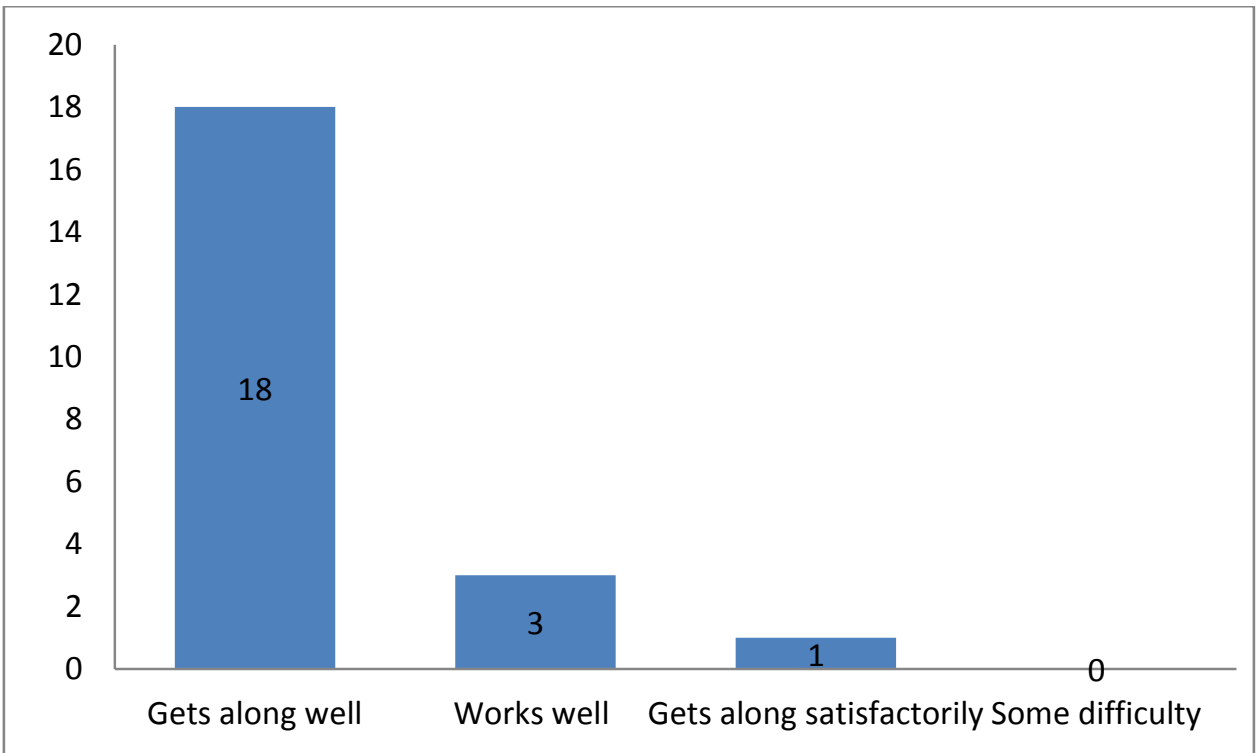

Figure 9. Relations with Others

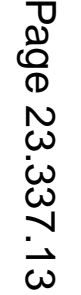






Figure 10. Judgment/Decision Making



Figure 11. Communication ability

rare occasions, students were ranked average in the multiple factors of evaluation including attitude/application to learning, ability to learn, dependability, writing ability, quality of work contributions, relations with others, judgment/decision making, and communication ability. 68\% of the students were found to be employable for experienced level positions while $27 \%$ was deemed to be eligible for entry level positions, making $95 \%$ of the students pass the engineering preparedness test of the employers. Only 5\% of the students needed additional knowledge and skill preparation for employment according to the employers. 


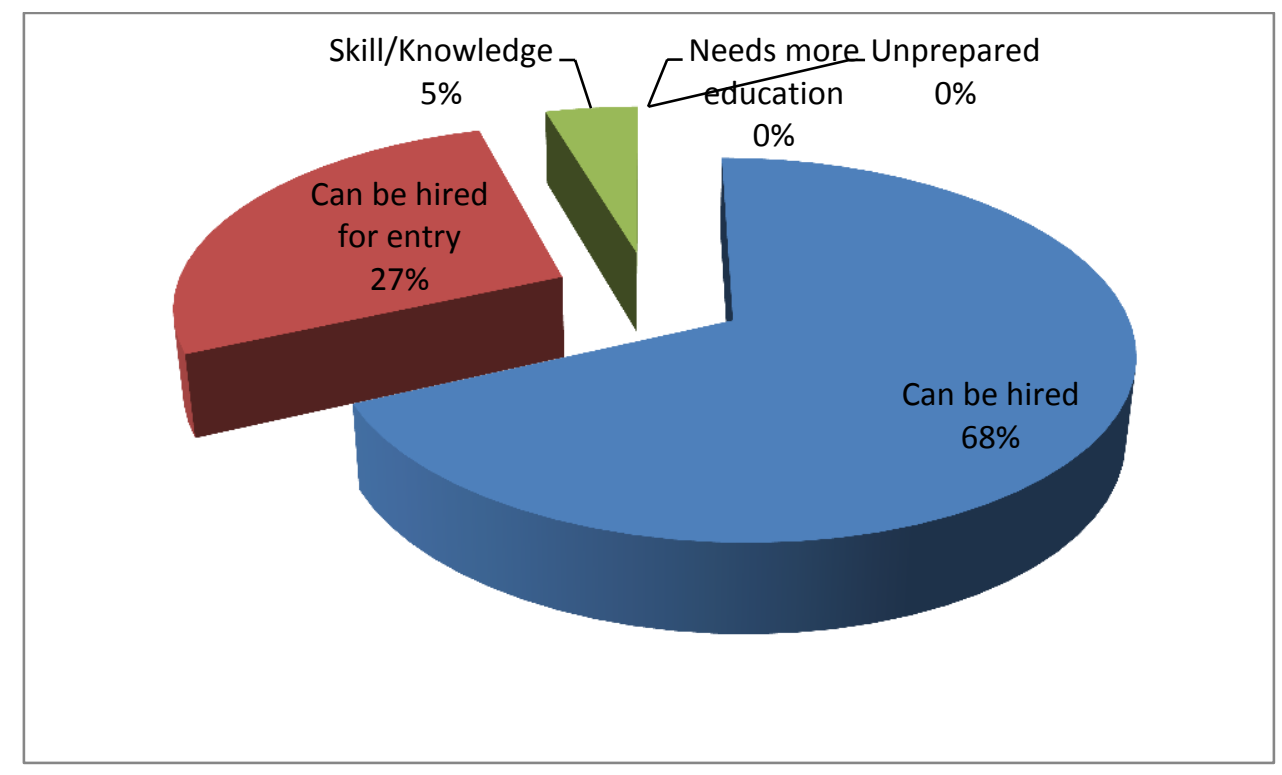

Figure 12. Engineering Preparedness

\section{Conclusions and Future Work}

Mandatory internships are a crucial part of this engineering department providing additional hands-on or practical experiences to its students. The student performance and the supervisor feedback are included within the outcomes assessment reporting for the ABET accreditation purposes. Based on feedback from the students and internship supervisors, the department has modified the requirements of the course, for example from 25 - 50 page reports to a more realistic 10 - 15 page one. Internal and external research experiences also helped improve student preparation. Students have been exposed to industrial grade laboratory equipment on an individual basis during the in-house projects even though they may have utilized that certain equipment or process earlier in a limited fashion. Some also have been working with novel engineering equipment and tools in their host institutions during the off-campus experiences.

The authors strongly feel that in-house and off-campus programs present invaluable experiences to their students. However, experiencing a sudden shift from a mainly teaching institution to a one that research demands are gaining momentum forces improvements to be made, mainly in the traditions and structures of the programs. There is another down side in involving students in the research programs. Even though they channel students to research positions and possibly graduate study, they take them away from industrial preparation and industrial positions. Most of these positions, no matter what they are, challenge the students into greater extent and boost their self-confidences. The students have to also prepare reports and memos, make presentations, and communicate effectively in writing and verbally as well as perform effectively as engineers and teams members in various work-environments. Making the engineering practice mandatory not only helps prepare students technically and professionally, but also improves their chances for employment before graduation. 


\section{References}

[1] Dunn, R., \& Carbo, M. (1981). Modalities: An Open Letter to Walter Barbem Michael Milone and Raymond Swassing. Educational Leadership, 381-382.

[2] Bloom, B. S., \& Krathwohl, D. R. (1956). Taxonomy of Educational Objectives, Handbook I: The Cognitive Domain. New York, NY, U.S.A.: David McKay Co. Inc.

[3] Kolb, D. A. (1984). Experiential Learning: Experience as the Source of Learning and Development. Englewood Cliffs, New Jersey, U.S.A.: Prentice Hall.

[4] Academic Internship Program. Academic Major Requirements.

http://www.rmu.edu/web/cms/student-life/career-center/student-services/exploring-career-

options/aip/Documents/program-academic-major-requirements.pdf

[5] Syllabus for ENGR 4900 Engineering Practice

[6] Southwest Florida Water Management District. Hotel and Motel Checklist, http://www.tampagov.net/dept_Water/files/Forms_Publications/Fact_Sheets_Brochures/Fact_Sheet_Hotel_Checklis t.pdf 


\section{Appendices}

\section{Engineering - Internship-Supervisor Evaluation}

For each of the following performance characteristics please place an " $x$ " in the line that best reflects your experience with this student. Thank you so very much!

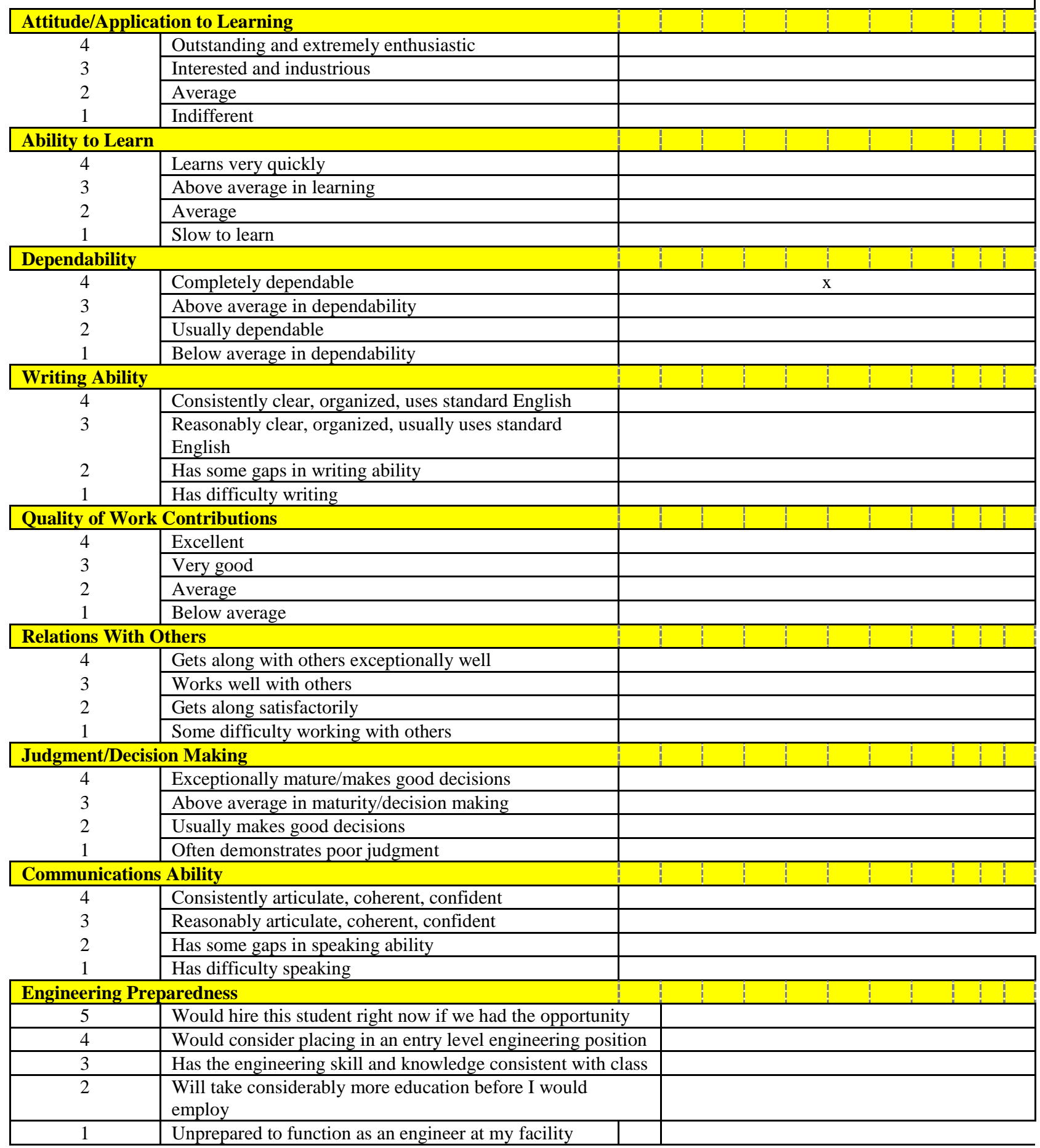

\section{Table 1. Employer Evaluation Form}


Internship Surrey

\begin{tabular}{|l|l|l|l|l|l|}
\hline My Engineering major is: & Biomedical & Industrial & Manufacturing & Mechanical & Software \\
\cline { 2 - 7 } (place an " $x$ " under yours) & & & & & \\
\cline { 2 - 6 }
\end{tabular}

Surrey Questions

\begin{tabular}{|c|c|c|c|c|c|c|}
\hline In my internship: & $\begin{array}{c}\text { Not } \\
\text { applicable }\end{array}$ & $\begin{array}{l}\text { Strongly } \\
\text { Disagree }\end{array}$ & Disagree & Neutral & Agree & $\begin{array}{l}\text { Strongly } \\
\text { Agree }\end{array}$ \\
\hline $\begin{array}{l}\text { I applied knowledge of } \\
\text { mathematics, science and } \\
\text { engineering. }\end{array}$ & & & & & & \\
\hline $\begin{array}{l}\text { I designed and conducted } \\
\text { experiments, as well as } \\
\text { analyzed and interpreted data. }\end{array}$ & & & & & & \\
\hline $\begin{array}{l}\text { I designed a system, } \\
\text { component, or process to meet } \\
\text { desired needs. }\end{array}$ & & & & & & \\
\hline $\begin{array}{l}\text { I functioned on multi- } \\
\text { disciplinary teams. }\end{array}$ & & & & & & \\
\hline $\begin{array}{l}\text { I identified, formulated, and } \\
\text { solved engineering problems. }\end{array}$ & & & & & & \\
\hline $\begin{array}{l}\text { I fully understood professional } \\
\text { and ethical responsibilities. }\end{array}$ & & & & & & \\
\hline I communicated effectively. & & & & & & \\
\hline $\begin{array}{l}\text { I used the broad education } \\
\text { necessary to understand the } \\
\text { impact of engineering solutions } \\
\text { in a global and societal context. }\end{array}$ & & & & & & \\
\hline $\begin{array}{l}\text { I recognized the need for life- } \\
\text { long learning and I can engage } \\
\text { in it. }\end{array}$ & & & & & & \\
\hline $\begin{array}{l}\text { I have been aware of } \\
\text { contemporary issues. }\end{array}$ & & & & & & \\
\hline $\begin{array}{l}\text { I used the techniques, skills, } \\
\text { and modern engineering tools } \\
\text { necessary for engineering } \\
\text { practice. }\end{array}$ & & & & & & \\
\hline
\end{tabular}

Table 2. Student Internship Survey 